\title{
Emergency autologous vein graft reconstruction after using a vascular closure device
}

\author{
Reconstrução de emergência de enxerto autólogo de veia após uso de dispositivo de fechamento vascular
}

\author{
Giel G. KONING ${ }^{1}$, Nasir A. SAYED ${ }^{1}$, J. Adam VAN DER VLIET ${ }^{2}$
}

RBCCV 44205-1279

\section{Abstract}

An emergency operation for access related acute critical limb ischemia with signs of infection is described. Inguinal femoral reconstruction was performed with a bifurcated graft constructed from the ipsilateral saphenous vein.

Descriptors: Iliac Artery. Femoral Artery. Arteriosclerosis. Angiography. Angioplasty.

\section{INTRODUCTION}

Manual compression has been the traditional means of haemostasis after femoral artery catheterization. Complications range from $1 \%-5 \%$, including hematoma, bleeding, arterialvenous fistulae and pseudo-aneurysms [1].

This led to the development of vascular closure devices (VCDs). Advantages over manual compression include reduced hemostasis time, quicker ambulation, improved comfort, earlier discharge and fewer complications [1-3]. Angio-Seal is composed of an absorbable collagen sponge and a specially designed absorbable polymer anchor

1. MD; Vascular Surgeon.

2. MD; PhD; Vascular Surgeon.

This work was carried out at the dept. of Surgery, Radboud University Nijmegen Medical Centre, The Netherlands

\section{Resumo}

Uma operação de emergência relacionada à isquemia aguda com sinais de infecção é descrita. Reconstrução femoral inguinal foi realizada com um enxerto bifurcado feito a partir da veia safena ipsilateral.

Descritores: Artéria Ilíaca. Artéria Femoral. Arteriosclerose. Angiografia. Angioplasty.

connected by an absorbable self-tightening suture. The device seals and sandwiches the arterial wall between the anchor and sponge. Notwithstanding the favorable reports, application of Angio-Seal is not without complications [4].

In this report we describe an emergency operation for access related acute critical limb ischemia with signs of infection after previous endovascular intervention using Angio-seal. An urgent inguinal artery reconstruction was performed with a bifurcated graft constructed from the ipsilateral saphenous vein. A medical drawing was made to illustrate this technique.
Correspondence address: Giel G. Koning

Geert Grooteplein-Zuid 10, Nijmegen - Holanda

E-mail: g.koning@chir.umcn.nl 


\section{CASEREPORT}

A 63-year-old man underwent an endovascular desobstruction of the left popliteal artery through a right groin access. At the end of the procedure a vascular closure device (AngioSeal ${ }^{\text {TM }}$ VIP, St Jude Medical, Minnetonka, USA) was employed. One day after intervention he complained of progressive right leg pain. The clinical diagnosis of an acute vascular obstruction was established and CT angiography demonstrated an occlusion of the right commune femoral artery (Figure 1). An access related

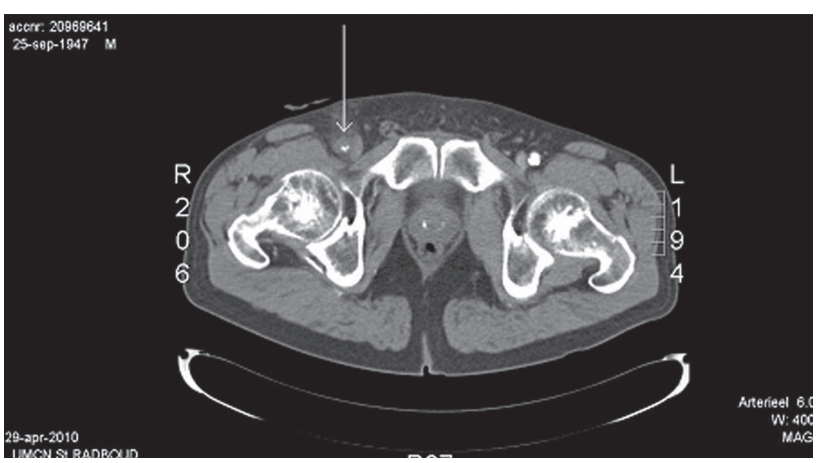

Fig. 1- CT angiography, occluded right commune femoral artery, Angio Seal visible

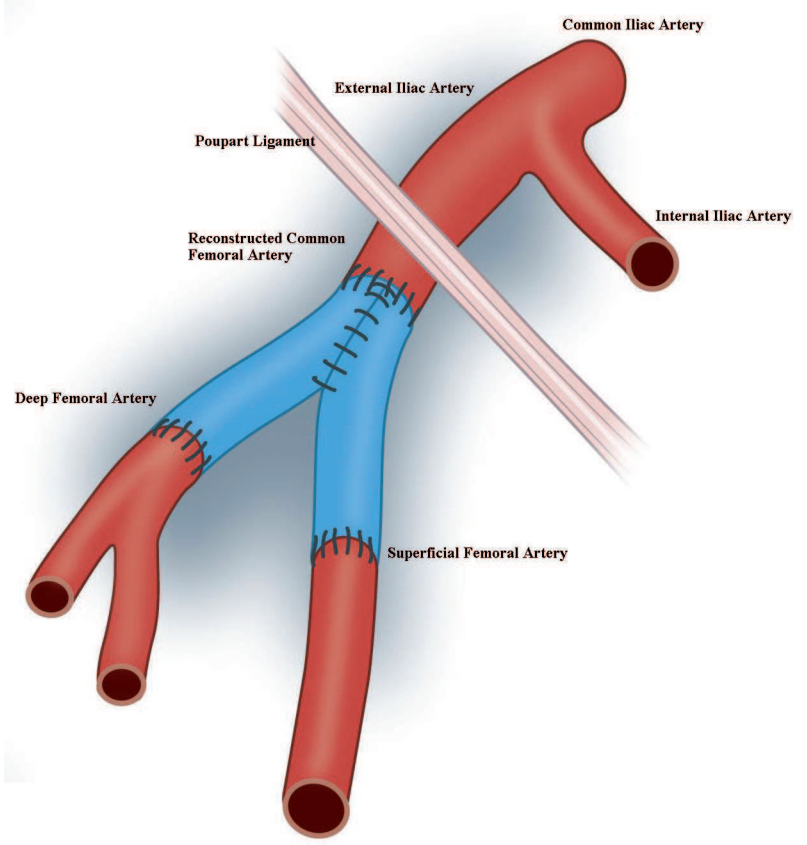

Fig. 2 - Ipsilateral saphenous vein harvested and transformed to a bifurcated interposition graft between the external iliac-and the superficial and deep femoral arteries obstruction was suspected and an immediate inguinal thrombendarterectomy was performed.

On exploration the anterior aspect of the common femoral artery appeared (already) with signs of inflammation of the surrounding tissue. Prosthetic reconstruction was considered inexpedient under these circumstances. Therefore the ipsilateral saphenous vein was harvested and transformed to a bifurcated interposition graft between the external iliac- and the superficial and deep femoral arteries (Figure 2). The blood flow to the limb was restored. Postoperatively the patient was treated with coumarin derivates. An expected wound infection, later on, was treated with drainage and IV antibiotics. Complete recovery occurred and a duplex ultrasound examination after 6 weeks and 6 months demonstrated a patent bypass.

\section{DISCUSSION}

Extensive experience with VCDs has been reported in cardiology randomized trials. Two recent meta-analyses, however, show that the overall reported advantages of VCDs over manual compression should be interpreted cautiously [4].

Few studies have been reported on the use of AngioSeal in peripheral arterial disease (PAD) [1]. To minimize adverse events, the authors suggested guidelines for the use of Angio-Seal in patients.

In vascular patients wound infections are common because of the inappropriate vascular state of the tissues. Wound infections after vascular reconstruction are hazardous. Prosthetic infections are not uncommon, especially in the groin [5,6]. They are associated with a high morbidity rate and are difficult to treat. Therefore vascular reconstruction with autologous material is preferred in compromised environments. Other causes of non-arteriosclerotic related arterial occlusions, such as the VCD's, are dissection, thrombotic clots after classic or endovascular aortic aneurysm repair.

In the present case, a bifurcated interposition graft was constructed from autologous saphenous vein in a way that is comparable to the Nevelsteen technique for aorto-iliac reconstruction with autologous femoral venous material [7]. After harvesting the ipsilateral saphenous vein, it was cut into 2 parts. Considering the original flow and the valves in the vein, we constructed an autologous vein graft. For the anastomoses we used a prolene 6.0 wire. As we expected the wound infection occurred and was treated with drainage and antibiotics. After 6 weeks and after 6 months, the bypass was still patent. There were no further events.

In conclusion, when confronted preoperatively with signs and symptoms of an infected area with prosthetic material, this technique can be considered for limb salvation. The use of VCD's is not without risks for serious adverse events. 


\section{REFERENCES}

1. Abando A, Hood D, Weaver F, Katz S. The use of the Angioseal device for femoral artery closure. J Vasc Surg. 2004;40(2):287-90.

2. Martin JL, Pratsos A, Magargee E, Mayhew K, Pensyl C, Nunn $\mathrm{M}$, et al. A randomized trial comparing compression, Perclose Proglide and Angio-Seal VIP for arterial closure following percutaneous coronary intervention: the CAP trial. Catheter Cardiovasc Interv. 2008;71(1):1-5.

3. Chevalier B, Lancelin B, Koning R, Henry M, Gommeaux A, Pilliere R, et al; HEMOSTASE Trial Investigators. Effect of a closure device on complication rates in high-local-risk patients: results of a randomized multicenter trial. Catheter Cardiovasc Interv. 2003;58(3):285-91.
4. van der Steeg HJ, Berger P, Krasznai AG, Pietura R, Schultze Kool LJ, van der Vliet JA. Acute arterial occlusion after deployment of the Angio-Seal closure device: is it as uncommon as we think? Eur J Vasc Endovasc Surg. 2009;38(6):715-7.

5. Wilson SE. New alternatives in management of the infected vascular prosthesis. Surg Infect (Larchmt). 2001;2(2):171-5.

6. Gutowski P. Aortoiliac graft infection as a diagnostic and treatment problem. Ann Acad Med Stetin. 1998;Suppl 41:1-72.

7. Nevelsteen A, Lacroix H, Suy R. The superficial femoral vein as autogenous conduit in the treatment of prosthetic arterial infection. Ann Vasc Surg. 1993;7(6):556-60. 